UCRL-JC-131121

Preprint

\title{
Start-Up Plan for the First NIF Laser Bundle: Transition from Single Beamlet Prototype to 192-Beamline Laser Facility
}

\author{
B. M. Van Wonterghem \\ D. R. Speck \\ D. Tiszauer \\ M. A. Lane
}

This paper was prepared for submittal to

Third Annual International Conference on Lasers for Application (SSLA)

to Inertial Confinement Fusion (ICF)

Monterey, CA

June 7-12, 1998

September 24, 1998

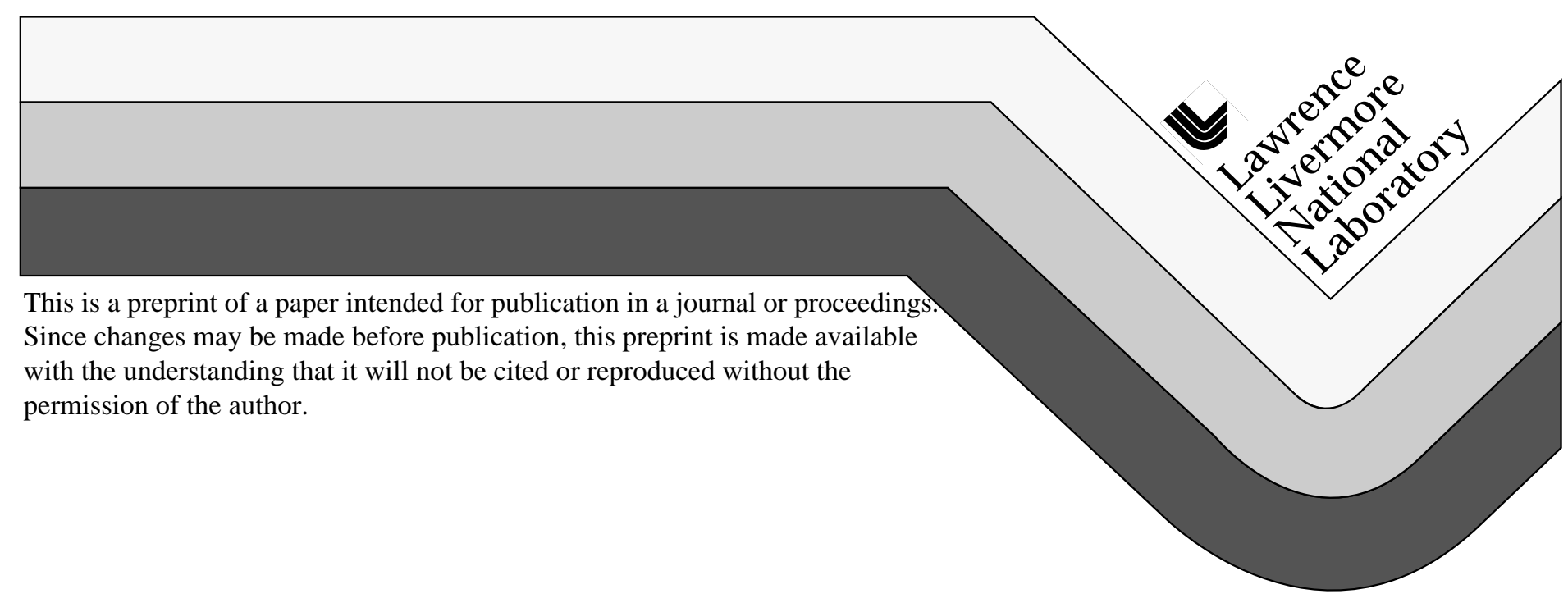




\section{DISCLAIMER}

This document was prepared as an account of work sponsored by an agency of the United States Government. Neither the United States Government nor the University of California nor any of their employees, makes any warranty, express or implied, or assumes any legal liability or responsibility for the accuracy, completeness, or usefulness of any information, apparatus, product, or process disclosed, or represents that its use would not infringe privately owned rights. Reference herein to any specific commercial product, process, or service by trade name, trademark, manufacturer, or otherwise, does not necessarily constitute or imply its endorsement, recommendation, or favoring by the United States Government or the University of California. The views and opinions of authors expressed herein do not necessarily state or reflect those of the United States Government or the University of California, and shall not be used for advertising or product endorsement purposes. 
UCRL-JC-131121

Start-up plan for the first NIF laser bundle: transition from single Beamlet prototype to 192-beamline laser facility $^{1}$

\author{
B.M. Van Wonterghem, D.R. Speck, D. Tiszauer, and M.A. Lane \\ University of California \\ Lawrence Livermore National Laboratory \\ PO Box 5508, L-493 Livermore, CA 94551-9900 \\ (510) 423-9494 / FAX (510) 423-4606
}

\begin{abstract}
The compact multi-pass laser design and the extensive use of optical component assemblies as line replaceable units (LRU) are essential to achieve the cost efficiency of the National Ignition Facility design. These design philosophies require a new approach to start-up operation of the NIF 192-beam-line high-energy laser compared to existing fusion laser facilities. The limited access to the beam-line optics and the limited on-line verification and maintenance capability require that extensive component verification and alignment take place in off-line facilities before the LRU's are installed in the laser structure.
\end{abstract}

We are developing a detailed plan for the start-up of the NIF facility. This plan includes systematic off-line component and LRU verification tests, LRU installation and prealignment, and sub-system acceptance tests, followed by a well defined set of operational test procedures to verify integrated performance. During integrated performance testing laser performance parameters of individual beam lines will be verified using a precision diagnostic system located in the NIF switchyard. If additional on-line calibration or performance testing is required, the LRU based architecture can accommodate the insertion of specialized in-line diagnostic LRUs at locations that require such additional testing during start-up. Multiple beam focal spot characteristics on disk targets in the NIF target chamber will be examined using X-ray diagnostics.

We will discuss the detailed plan for the startup of the first bundle of 8 beam lines, a laser system by itself similar in size and complexity to the LLNL Nova laser, The discussion will include the application of lessons learned from start-up and operation of the Beamlet prototype beam line during the last 4 years. Experience on the first bundle of beams is essential to optimize the start-up procedures to expeditiously deliver the 23 remaining laser bundles to the operations program at the rate of one bundle per month to complete the NIF facility.

The plan that we describe supports a gradual transition from the present ICF program based upon the 10-beam Nova laser system to an ICF program based upon the 192-beam-line National Ignition Facility, with all 24 bundles being available for operation in FY04. This plan includes a schedule for a phased bundle-by-bundle completion of integrated operational test procedures and hand over of laser bundles to the program for experimental operations. The early start-up of one bundle provides early experimental capability two years before completion of the NIF Project, and experience that will be essential to complete this transition plan on schedule in a cost effective way.

\title{
I. INTRODUCTION
}

The National Ignition Facility ${ }^{1}$ (NIF) is a high-power laser facility being constructed to support the United States Stockpile Stewardship and Management Program, inertial fusion ignition-physics experiments, weapons effects testing, and other research efforts in the area of high-energy-density physics and astrophysics ${ }^{2,3}$. The NIF laser driver consists of 192 laser beams, similar in design to that of the Beamlet scientific prototype ${ }^{4}$, arranged in 24 bundles of 8 beams. Each bundle is split into 2 beam quads of 4 beams, each of which is transported to the target chamber as a group. There each quad is frequency converted from $1.05 \mu \mathrm{m}$ to $0.351 \mu \mathrm{m}$ and focused onto the center of a 10 meter diameter evacuated target chamber in a common Final Optics Assembly. Figure 1 shows an isometric view of the NIF facility. By the completion of the NIF Construction Project at the end of FY03, all 24-laser bundles will have been installed in the facility, and all 12-laser

${ }^{1}$ This work was performed under the auspices of the United States Department of Energy by Lawrence Livermore National Laboratory under contract number W-7405-ENG-48. 
bundles in the first laser bay will be fully operational. Full operation of all 24 NIF laser bundles is expected by the end of FY04. In order to minimize the time between shutdown of the 10-beam Nova laser facility at LLNL and commencement of target physics experiments in the NIF, a transition plan was adopted which calls for bundle-by-bundle laser start up, and ICF Program operation of each bundle for experiments as it successfully completes its operational test requirements. In this manner Program experiments capability can begin in early FY02 following start-up testing of the first laser bundle and nearly two years before Project completion.

The NIF facility consists of two laser bays, each housing 12 laser bundles; two switchyards, which contain the transport optics to direct the beams to the target bay; and a target bay, which contains the final beam transport mirrors, frequency conversion and focusing optics, and the target chamber with the target support and diagnostic equipment.. In the switchyards, each bundle is split vertically into two beam quads $(2 \times 2$ beam lines), one of which illuminates the target, located at the center of the chamber, from the top hemisphere, while the other illuminates the target from the bottom hemisphere of the chamber. The chamber itself is an evacuated 10-meter-diameter aluminum sphere located in a target bay designed to provide shielding against radiation that results from target experiments. The transition plan takes advantage of the modularity of the facility to proceed in four consecutive phases. Figure 2 shows schematically the status of the facility during these phases. The modularity is fundamental to the transition plan, as it allows installation, acceptance testing and start-up in one laser bay, concurrent with limited operation of one or more laser bundles in the other laser bay. This is particularly important during the start-up and operation of the first bundle and the concurrent installation of special equipment and laser bundle start up in laser bay 1.

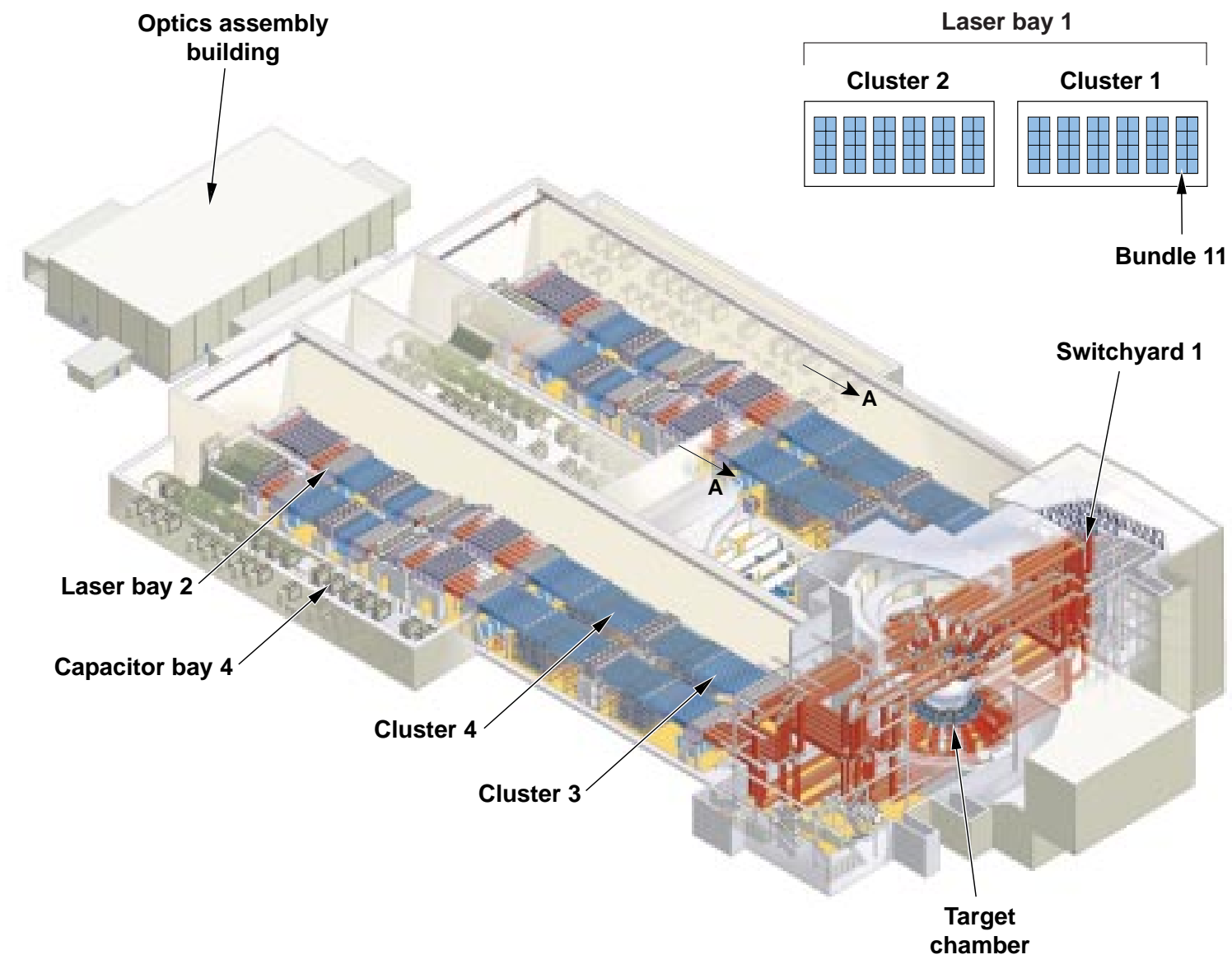

40-00-0996-2100pb02

Figure 1. Isometric layout of the NIF facility (Title I status), showing the two laser bays, two switchyards with the central target bay housing the $10 \mathrm{~m}$ diameter evacuated target chamber. Adjacent to each laser bay are two bays which house the capacitor banks to drive the flash lamp pumped laser amplifiers. A separate clean room building for LRU assembly and maintenance is located at the end of the laser bays. 


\section{End of FY01}

Early beam bundle-

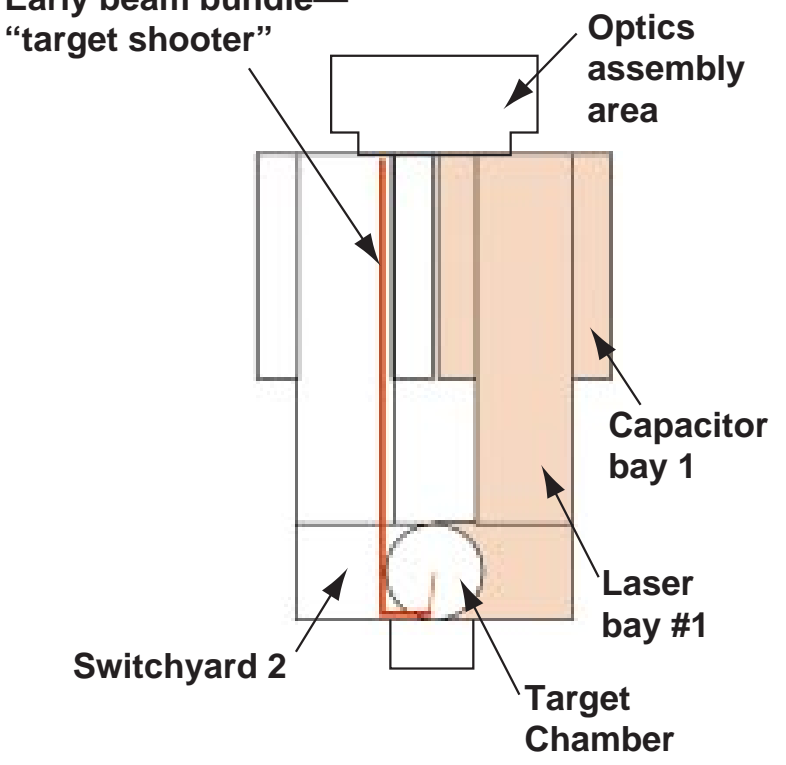

End of FY03

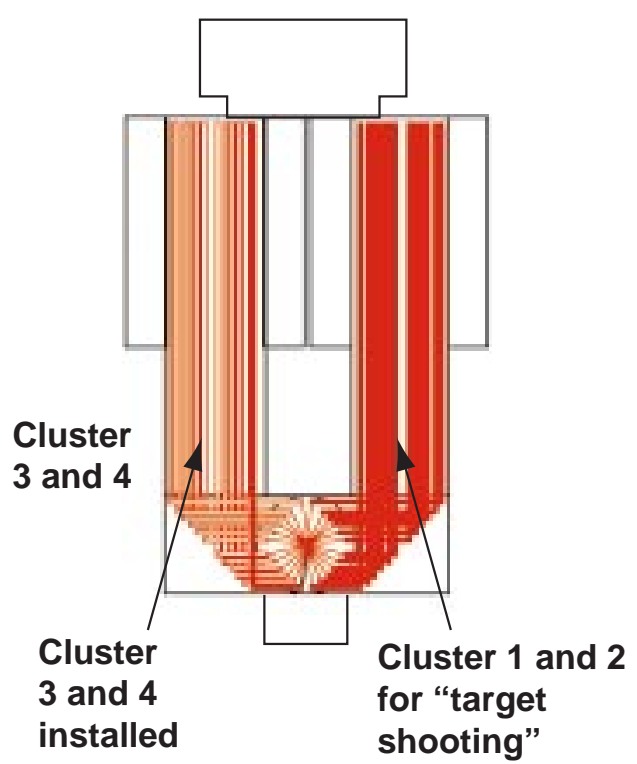

\section{End of FY02}

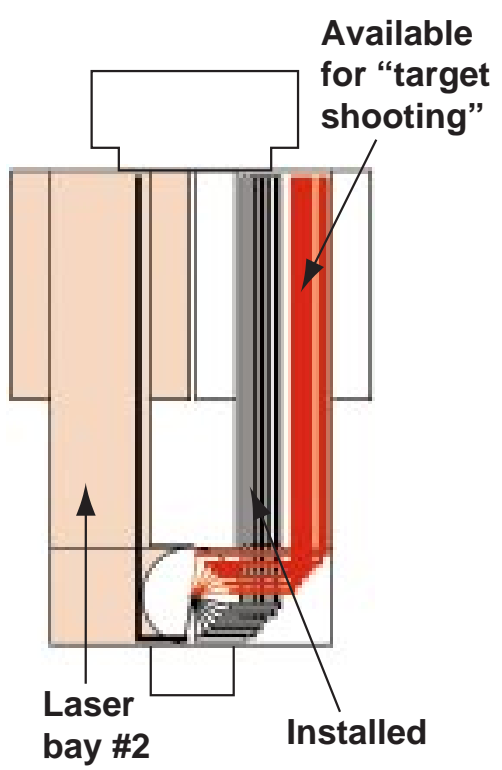

Installation/construction activity area

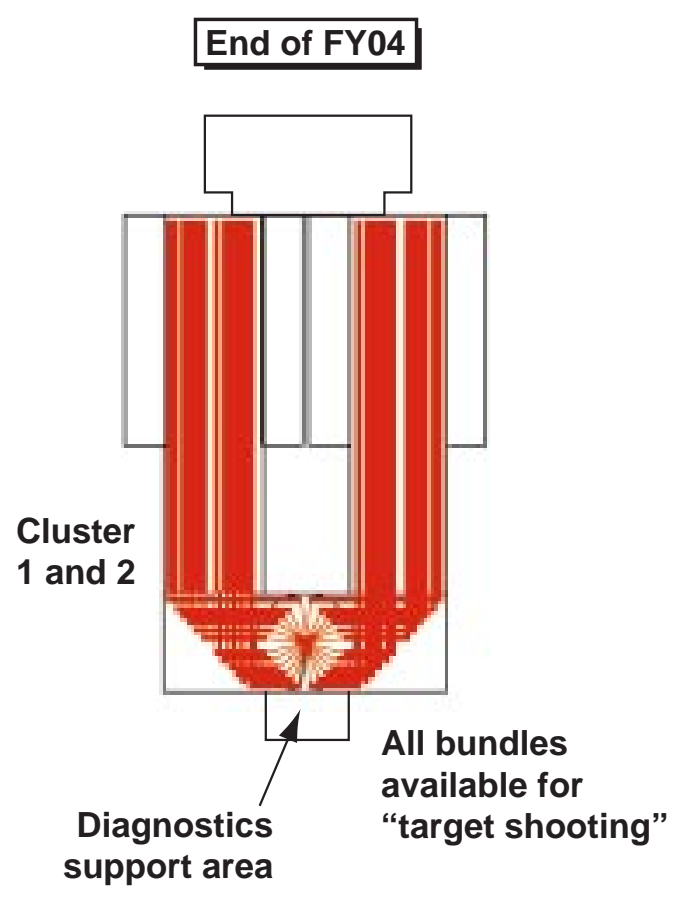

Figure 2. Schematic representation of the 4 phases of the transition plan to a fully operating NIF facility with early first bundle experimental capability concurrent with installation and start-up. The planned status of the facility at the end of FYs $01,02,03$, and 04 is shown. 


\section{NIF START-UP}

NIF Start-up testing is defined as the integrated performance testing that follows installation and acceptance testing of subsystems, structures and components in the facility. The initial laser performance requirements for NIF during start-up shown in figure 3 are called out in the NIF Project Completion Criteria and are based on the NIF Functional Requirements and Primary Criteria. The start-up requirements are downgraded to take into account the limited operational experience at start up and the optics conditioning required to achieve NIF optical damage fluences. The start-up requirements were used in the flow down into acceptance criteria for the individual operational test procedures to be conducted during the start-up phase of the NIF laser. The NIF Functional Requirements and Primary Criteria on all bundles will be verified later during NIF operations, after experience with the actual hardware has been obtained and the optics conditioning and associated optics damage statistics have been verified. The Project Completion Criteria require that at least one bundle has demonstrated the full FR and PC before the NIF Construction Project completion at the end of FY 03.

The start-up strategy for a NIF bundle differs significantly from the approach followed for more conventional MOPA laser architectures, and the Beamlet laser, a nearly full scale single beam line prototype of the NIF multi-pass architecture ${ }^{4}$. The activation of these systems was achieved by aligning and testing the pulse generation system, followed by the individual amplification stages, transport optics and frequency converters. In the case of the Beamlet laser, the pulse generation was activated and tested first, in parallel with dedicated main amplifier gain and wavefront tests. In the next phase, the injected beam was double passed through the main cavity amplifier, followed by full cavity operation and activation of the booster amplifier and transport spatial filter. The last phase consisted of the frequency converter activation

\begin{tabular}{|c|c|c|}
\hline Parameter & $\begin{array}{l}\text { Primary criteria and } \\
\text { functional requirements }\end{array}$ & Start-up requirement \\
\hline $3 \omega$ energy & $9.4 \mathrm{~kJ} /$ beam & $>5 \mathrm{~kJ} /$ beam \\
\hline $3 \omega$ peak power & $2.6 \mathrm{TW} / \mathrm{beam}$ & $>2 \mathrm{TW} /$ beam \\
\hline Pulse spot size & $\begin{array}{l}9.4 \mathrm{~kJ} / 2.6 \mathrm{TW} / \mathrm{beam} \text { into } 600 \mu \mathrm{m} \\
\text { diameter spot }\end{array}$ & $\begin{array}{l}5 \mathrm{~kJ} / 2 \mathrm{TW} / \mathrm{beam} \text { into } 600 \mu \mathrm{m} \\
\text { diameter spot }\end{array}$ \\
\hline Positioning accuracy & $\begin{array}{l}50 \mu \mathrm{m} \text { RMS from TCR, any beam } \\
<200 \mu \mathrm{m} \text { from centroid }\end{array}$ & $<100 \mu \mathrm{m}$ RMS from TCR \\
\hline Beam power balance & $\begin{array}{l}8 \% \text { RMS deviation of power averaged } \\
\text { over any } 2 \text { ns interval }\end{array}$ & $\begin{array}{l}10 \% \text { RMS deviation of power } \\
\text { averaged over any } 2 \text { ns interval }\end{array}$ \\
\hline Beam smoothness & Spatial and temporal conditioning & $\begin{array}{l}\text { 1D-SSD systems installed and } \\
\text { aligned, } 3 \AA \text { bandwidth capability }\end{array}$ \\
\hline Pulse duration & $20 \mathrm{~ns}$ & $20 \mathrm{~ns}$ \\
\hline $\begin{array}{l}\text { Dynamic range } \\
(3 \omega \text { pulse) }\end{array}$ & $50: 1$ & $25: 1$ \\
\hline Prepulse power & $\begin{array}{l}\mathrm{I}<10^{8} \mathrm{~W} / \mathrm{cm}^{2}, 20 \mathrm{~ns} \text { time interval } \\
\text { preceeding pulse }\end{array}$ & $\begin{array}{l}\mathrm{I}<10^{8} \mathrm{~W} / \mathrm{cm}^{2}, 20 \mathrm{~ns} \text { time interval } \\
\text { preceeding pulse }\end{array}$ \\
\hline $\begin{array}{l}\text { Time between no } \\
\text { yield shots }\end{array}$ & $<8 \mathrm{~h}$ & $8 \mathrm{~h}$, recovery time measured \\
\hline
\end{tabular}

Figure 3. A table summarizing the National Ignition Facility functional requirements and the start-up requirements given in the NIF Project Completion Criteria. (TCR: target chamber center reference, 1D-SSD: one-dimensional smoothing by spectral dispersion). 
and test. The multi pass architecture of NIF, with injection in the transport filter, requires assembly and alignment of the complete $1 \mu$ laser to start beam propagation and component testing. In addition, the complex mechanical design of the optics support structures, and the strict cleanliness requirements make such a start-up approach risky and time consuming. The NIF start-up strategy is based on pre-aligned optical components installed as Line Replaceable Units (LRU's), together with an aggressive off-line test program of laser components (called Master Test Plan). The bundle-based start-up plan described in more detail below starts only after completion of the $1 \mu$ laser installation. This includes all mirrors, spatial filter lenses, amplifiers, Pockels cell, alignment and diagnostic systems and all beam enclosures up to the switchyard wall roving mirror enclosure, which houses safety shutters acting as beam dumps.

The prerequisite for the Start-up tests is an extensive set of component tests, LRU acceptance test procedures, and subsystem acceptance test procedures that will test the functionality of each major assembly and subsystem. The hierarchy of these tests and how they relate to the Start-up operational test procedures is shown schematically in figure 4 . Thorough pretesting is essential because of the limited ability to trouble shoot and repair LRUs on line and the time and resources required to replace a faulty unit. Also necessary at the start of the operations tests is a laser propagation and energetics performance model to use as an aid in setting up the system for shots and to predict system performance limits. This model will get its initial component data from AMPLAB prototype tests of amplifier performance and optics metrology. These measurements will be updated with data from the Start-up tests as they become available.

Start-up testing is performed on individual bundles. As presently constituted for the first bundle ${ }^{5}$, it consists of a set of 16 individual test procedures, which are completed in three distinct phases. Figure 5 shows a diagram of the 16 operational test procedures and which of the test procedures are included in each of the three phases. During the first phase, the main laser within the laser bay will be operationally tested. This includes activation and integration of all main laser components, the laser alignment and diagnostic systems, and associated integrated computer controls. This phase will complete with a demonstration of reproducible and reliable propagation and amplification of low power pulses in the

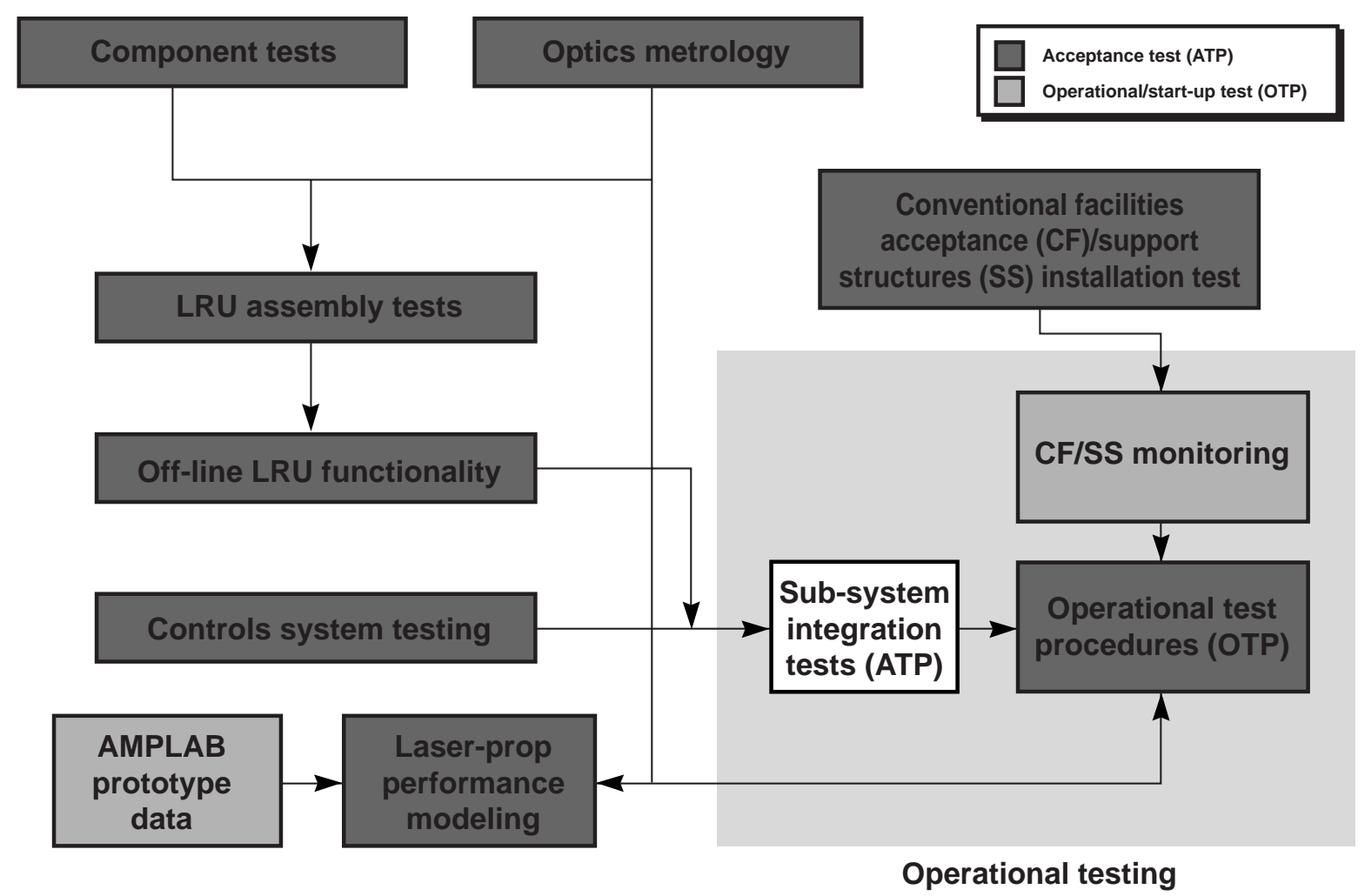

Figure 4. Operational testing will be preceded by component, line replaceable unit (LRU), and sub-system acceptance tests and supported by a computer model of laser performance. 


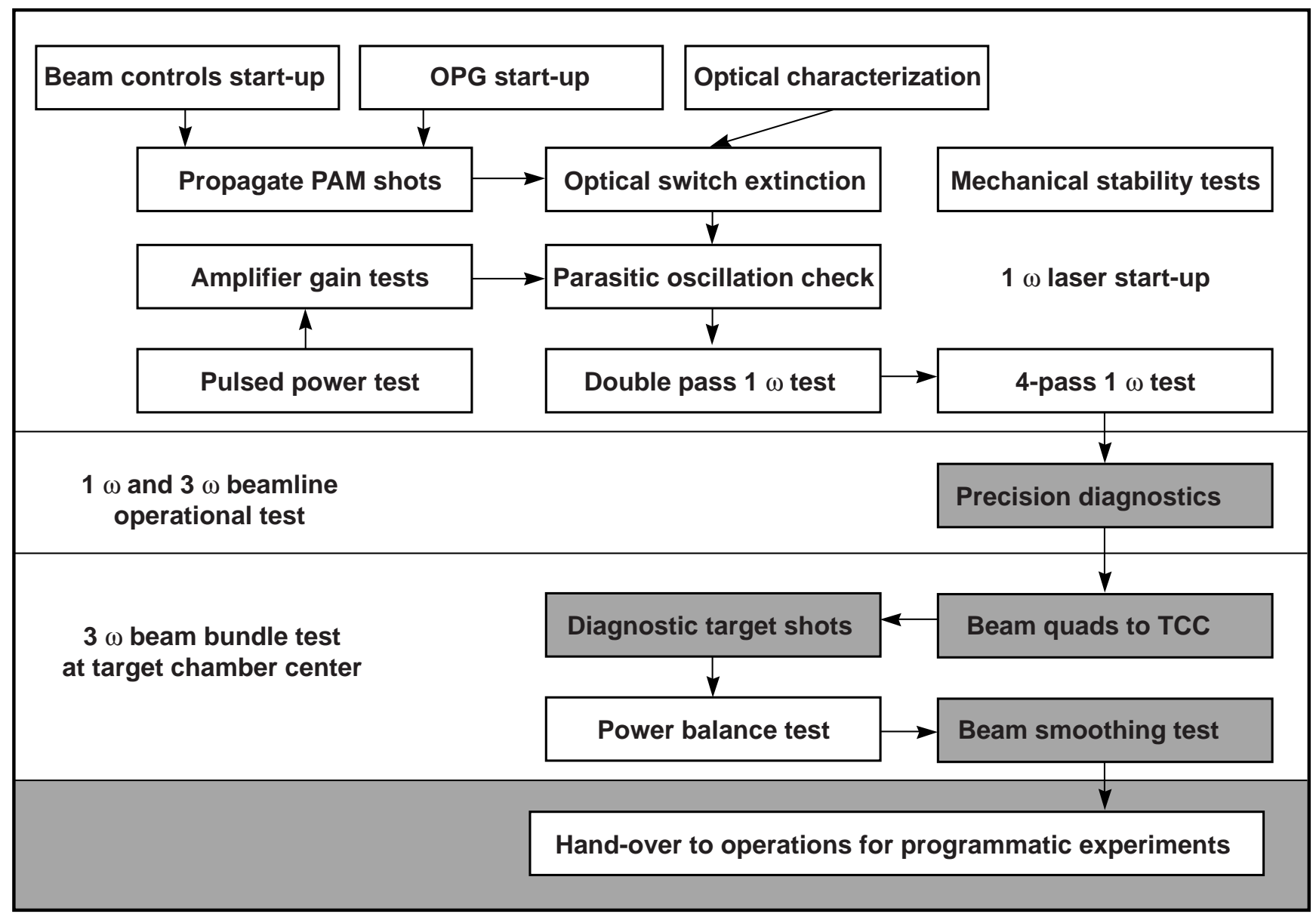

Figure 5. The start-up plan for an individual bundle consists of 16 operational test procedures divided into three consecutive phases. (OPG: optical pulse generation system, PAM: preamplifier module, TCC: target chamber center)

four-pass laser amplifier under integrated computer control and with diagnostics operational. A schematic drawing showing how the system would be set up to perform one of these tests, a double pass test with the alignment laser to measure the gain of the amplifier slabs connected to a single pulsed power module, is shown in figure 6 . Once reproducible and reliable operation has been confirmed, phase 2 testing will begin during which the precision diagnostic systems in switchyard 2 will be used to validate laser performance of individual beam lines under high intensity and long pulse conditions both at the fundamental wavelength ( 1 micron) and after frequency tripling $(0.35$ micron $)$. Beam properties measured at $0.35 \mathrm{~mm}$ include the energy, power, and spot size in the equivalent target plane. During the third phase, beam transport to the target chamber and through the final optics for both beam quads of each bundle will be completed. A final set of tests will then be conducted to verify laser performance at the target within the target chamber. Laser beam diagnostics will consist of the $1.05-\mathrm{mm}$ and $0.35 \mathrm{~mm}$ system diagnostics. The beams will be focused on special diagnostic targets and beam properties on the target will be measured with X-ray imaging diagnostics to verify beam pointing, synchronization and spot size. These diagnostic target shots are followed by tests of power balance controls and beam smoothing systems. A start-up test plan has been developed for the first NIF bundle, which describes in detail the individual steps and acceptance criteria for each of the 16 operational test procedures that constitute the start-up tests of an individual bundle.

The timetable for start-up of each bundle is shown in figure 7 including the schedule for Program operation and experiments following each bundle start-up. In the following sections we discuss in more detail the role of the first bundle in facilitating the start-up of the remainder 23 bundles, and the interaction of start-up and early experimental operations in the FY02-FY04 time period. 


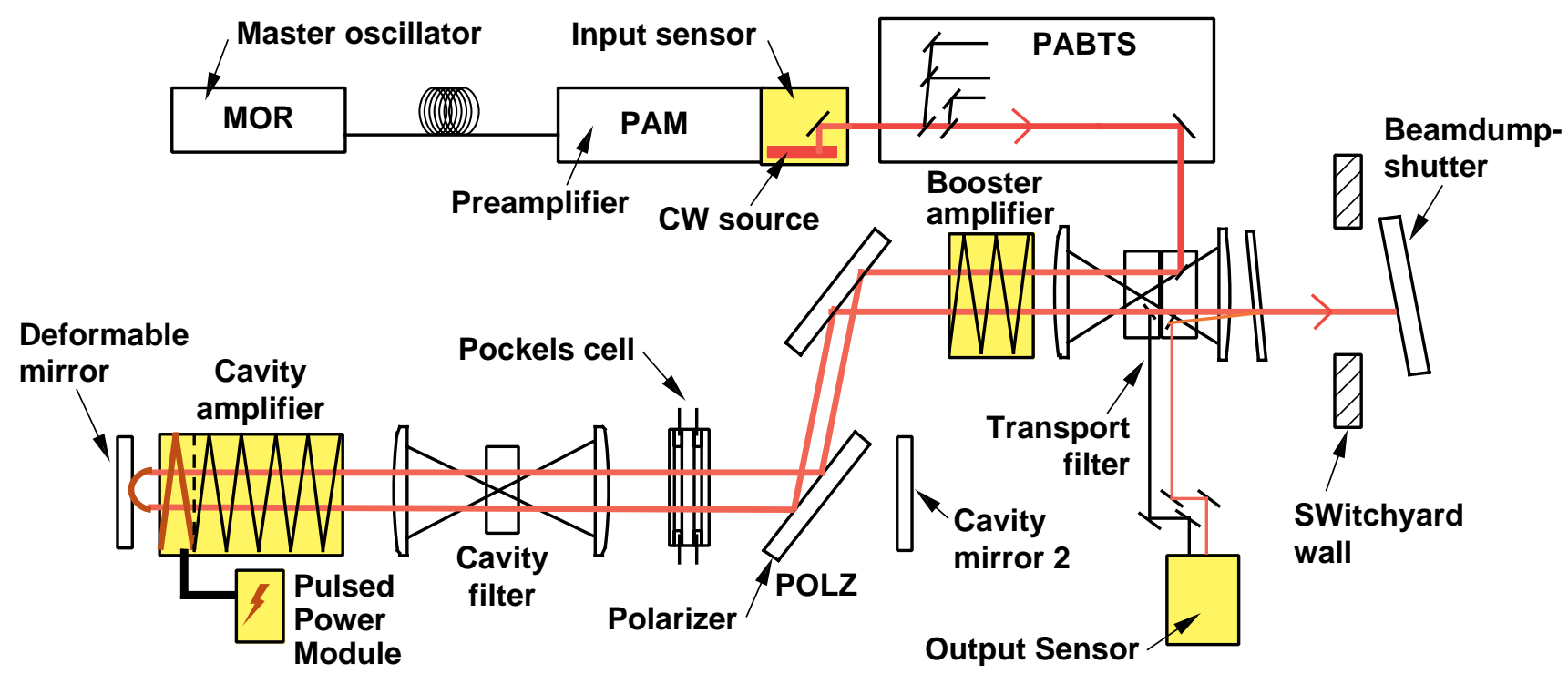

Figure 6. A schematic of a NIF laser beam line showing the beam path for one of the tests during the $1 \mu$ laser start up phase of the start-up plan. The test illustrated is a double pass test with the alignment laser to measure the gain of the amplifier slabs connected to a single pulsed power module.

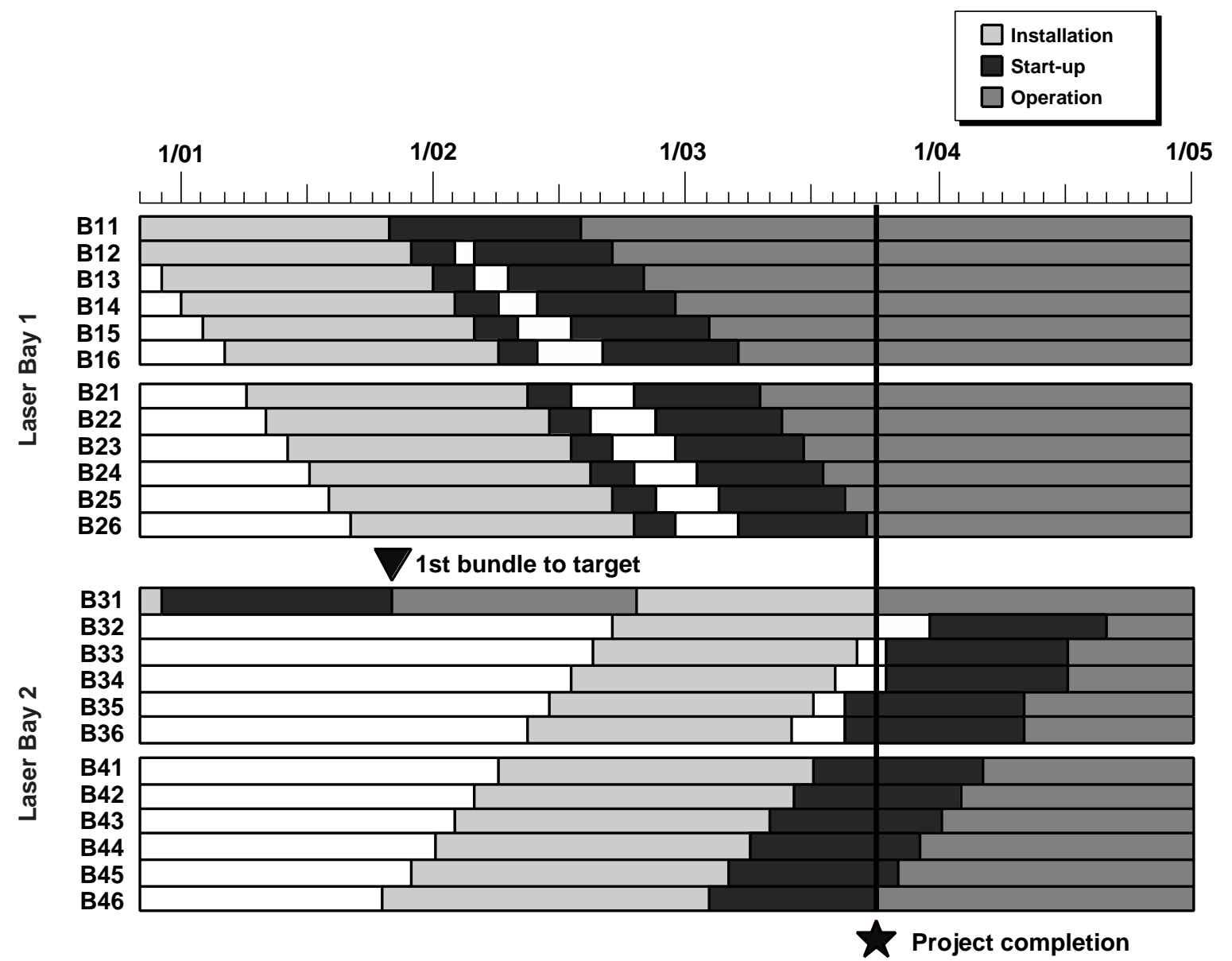

Figure 7. Time schedule for installation, start-up and hand-over to NIF operations for each of the 24 NIF bundles. The first bundle is Bundle 31, located in the second laser bay, next to the central operations area. Subsequent bundles will be activated starting in laser bay 1 , followed by laser bay 2 , each time going from the outside bundle to the central area. 


\section{START-UP AND OPERATION OF THE FIRST NIF BUNDLE}

Early first bundle start up on NIF serves several important purposes. First, it provides early feedback regarding the integration of NIF sub-systems into a working bundle of laser beamlines. Second, it provides training for operations personnel and a trial of test procedures so that they may be improved for the start-up of subsequent bundles. Third, it provides early experimental capability for NIF users.

The first bundle requires early start-up of the LRU assembly process. This process is a complex chain of activities that includes receiving and inspections, storage, precision cleaning, optics processing, LRU assembly and prealignment, and final acceptance tests prior to installation in the beam-line structures. During the installation of the remaining 23 bundles over 130 LRUs need to be completed per month. The first bundle provides the opportunity for a pilot run of this process, and allows a subsequent period of several months to correct and optimize process steps and procedures.

In order to start first bundle operation as early as possible and to increase the time between first bundle start up and the start of bundle assembly in laser bay 1, optical assemblies for the first bundle will be installed in Laser Bay 2 before final temperature stability in the bay is reached. Installation begins as soon as the laser bay is cleaned by the Conventional Facilities team. Optics assemblies are installed when temperature fluctuations are approx. $+/-5^{\circ} \mathrm{C}$. Final temperature control requirements are $+/-0.5^{\circ} \mathrm{C}$. The resulting increased alignment errors for the optical components will result in a slightly smaller clear aperture for the first bundle, estimated at $<5 \%$. In the worst case, this might lead to a $10 \%$ reduction in energy and power available for 1 st bundle experiments.

The early operation of the first bundle for experimental tests, concurrent with facility construction and start-up, provide a synergetic environment, where the laser performance and the target chamber support systems can be tested and optimized for the remaining bundles by the laser engineering and scientific staff. This facilitates a smooth transition to a fully operational facility and reduces the time interval required to build the system up to its full experimental capability. The first bundle will maintain the abilities of the scientific and engineering staffs by providing an operational facility with capability and complexity similar in size to existing facilities such as the Nova facility at LLNL and the OMEGA Upgrade at LLE, ${ }^{6}$ University of Rochester. The experienced staff required to run the large and complex NIF facility will grow in step with the facility, starting with the first bundle and increasing as new bundles become available one at a time during completion of the start-up process.

\section{START UP OF REMAINING 23 BUNDLES}

After the first bundle (Bundle 31 in Laser Bay 2) has been operational for nearly one year, start up of the first bundle of Cluster 1 in Laser Bay 1 will be completed and the bundle will be handed over to NIF operations. Starting from that time, start up of laser bundles in Laser Bay 1 will be completed at the rate of one bundle per month and one additional bundle will become available for user experiments each month until the completion of Laser Bay 1 start-up test procedures eleven months later. The start up of the laser bundles will be performed following a plan similar to that for the first bundle. We expect that the first bundle will have validated off-line verification techniques that the on-line tests therefore can be simplified. As more and more bundles become available, laser energy and power increase and concurrently the experimental capability of the facility will increase. This point is illustrated in figure 8 , which shows the increase in total energy available for target experiments as a function of time. The limited target diagnostic instrumentation implemented during the first bundle operation will be expanded over time to make use of the increasing laser capabilities to build toward the full planned diagnostic instrumentation suite.

Until Project completion at the completion of start-up tests in laser bay 1, there will be many challenges in orchestrating concurrent activities in one facility including, Conventional Facilities activation, equipment installation, startup activities, and first bundle experimental operations. The Project installation schedule has been structured to minimize conflicts with first bundle operation for as long as possible by installing the other 3 clusters of laser hardware before installing hardware in the same cluster as the first bundle. As shown in figure 7, the first bundle is forced to cease operation by the need to install adjacent hardware. Since the definition of the Project completion requires that Laser Bay 2 hardware only be installed, plans for realignment, refurbishment and restart of the first bundle are not yet worked out.

Start-up activities in the target area are on an equally tight schedule with many potential conflicts. The Target Bay is the latest in time for the completion and activation of Conventional Facilities, and thus will be the latest area to start 


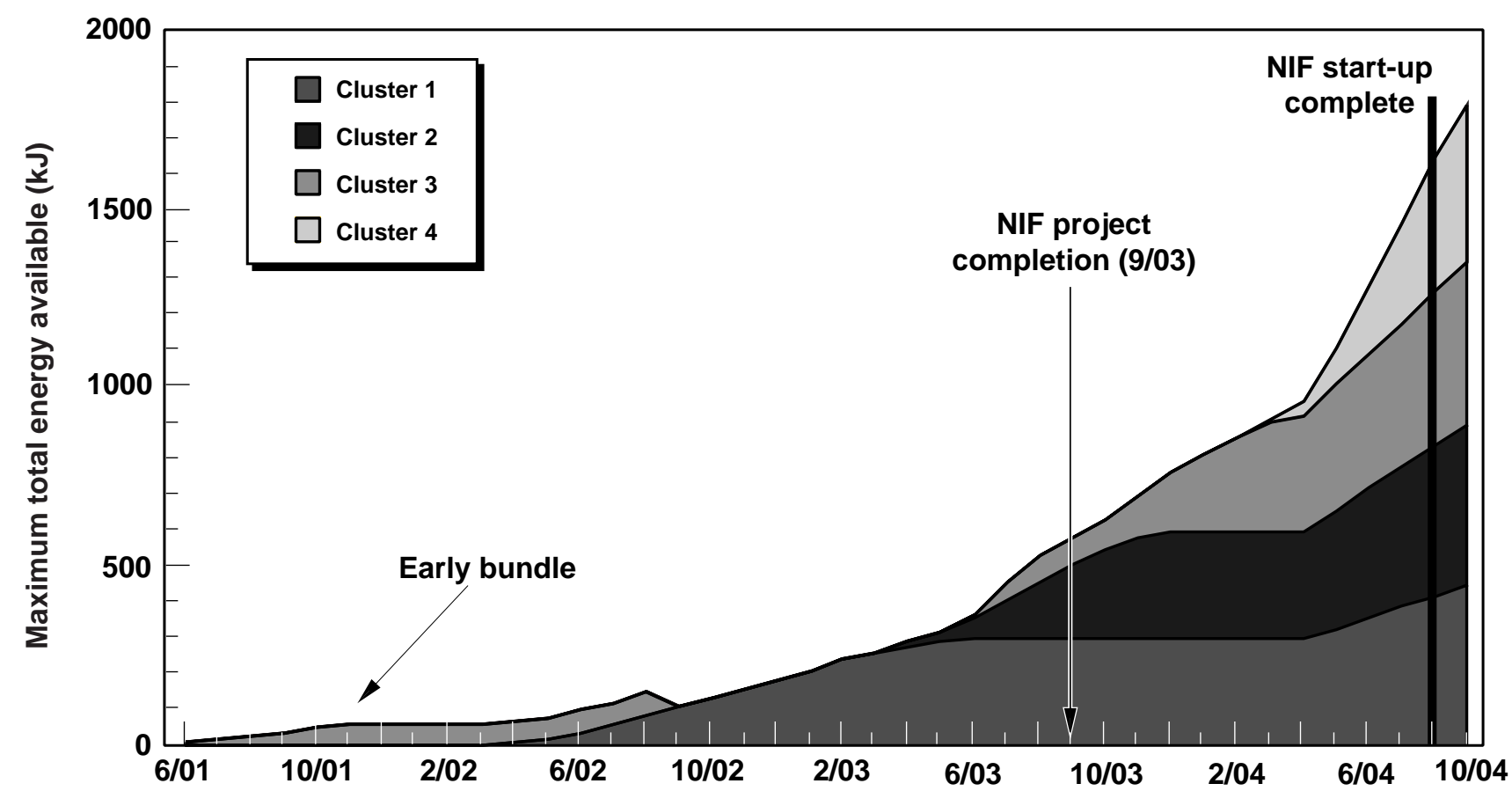

Figure 8. Maximum energy available from the NIF laser in the Indirect Drive configuration as a function of time during the initial operations period, concurrent with equipment installation and start-up. The gray scales indicate the energy ramp-up of the four individual clusters of 6 laser bundles each.

installation of special equipment. Alignment of the beam paths to the target chamber is more difficult because beam quads have a 3-D aspect not present in the laser bays and there are no plans for providing centering references for the beam turning mirrors. Establishing and maintaining a vacuum in the chamber after the installation of the final optics, and the installation alignment of the tripling crystals and the $0.35 \mu \mathrm{m}$ diagnostics can all potentially hold problems that create schedule delays. Unlike the other areas, start-up activities in the target bay are in direct conflict with shot operations. We are currently assuming one shift per day will be available for shot operations. This complex set of conflicting activities and the potential for schedule delays will require intelligent real time scheduling of target bay activities.

During the construction and installation phase of the Project, there will be a need for constant real-time changes in laser equipment installation plans, which will affect downstream activities in complex ways. An information system will be implemented to issue work orders and track over 20000 assembly, installation, acceptance test and operational test activities during the 3 years required to complete laser installation. This information system is linked to databases that manage parts inventory and contain optical component metrology data, results of individual acceptance and operational tests and shot archival data.

At the end of the NIF Construction project half of the 24 laser bundles will have been qualified and handed over to the NIF operations organization, and all the remaining special equipment will have been installed, acceptance tested, and ready for start-up testing during FY04. At that time a fully developed operations organization will be in place with a significant amount of operational experience. The start-up of the remainder 12 laser bundles in the second laser bay will proceed more rapidly than the laser bay 1 bundles (shown in figure 7). Simultaneous operation of all 24 bundles is expected to occur by the end of FY04, at which time the full energy of $1.8 \mathrm{MJ}$ will be available in the Indirect drive configuration.

\section{ICF PROGRAM EXPERIMENTS DURING AND UP TO COMPLETION OF START-UP}

After completion of the first bundle start-up activities early in the first quarter, this bundle will become available for target experiments throughout the remainder of FY02. Prior to first bundle operation for target experiments, the Project will complete an Operational Readiness review. As outlined earlier, Clusters 1 and 2 in Laser Bay 1 will subsequently become available for operation at the rate of one bundle per month starting late in FY02 up to Project completion at the end of 
FY03. The remaining 12 bundles of cluster 3 and 4 in Laser Bay 2 will become available to operations through FY04. At the hand-over to operations, the bundles will nominally operate at an energy of $5 \mathrm{~kJ}$ per beamline at $3 \omega$. The energy output will be ramped up to the nominal $75 \mathrm{~kJ}$ output per bundle over a sequence of shots commensurate with optics conditioning requirements and operational experience. This minimizes risks for early damage to optical components. The estimated total $3 \omega$ energy ramp-up rate corresponding to the bundle-by-bundle start-up is shown in figure 8 .

The Project's need for efficiency in laser equipment installation, required the bundle installation sequence as shown in figure 7. This sequence results in a non-symmetric target irradiation pattern during start-up. Figure 9 shows how each of the clusters is mapped onto one quadrant of the target chamber sphere and how the quads are arranged within the quadrants. At the end of FY03, the quads available cover one hemisphere, and the illumination mode of targets remains asymmetric until all bundles become available. This illumination asymmetry limits the expected yield from ignition experiments, but does not prevent a large array of experiments required to establish proper conditions of ignition, and to obtain important high energy density and weapons physics data. The system can also be used extensively to test and optimize new target diagnostics systems as they become available.

The number of target shots available during initial operations is limited by the concurrent installation and start-up during the project, and the concurrent completion of start-up during FY04. During the Project one shift per day will be available for shot operations, except for a small period of time near the end of FY03, when equipment installation in Laser Bay 1 has been completed. During most of FY04, two shifts of shot operations will be available. A plan has been compiled for the total number of target shots available, based on the assumption that each bundle can be fired once per 8 hour shot shift. This plan estimates the number of shots using all available bundles to be 400 by the end of the Project, and 884 by the end of FY04. When using subsets of bundles for target shots, more shots are available. The total number of target shots per shift is limited to three shots, based upon operational and start-up considerations.

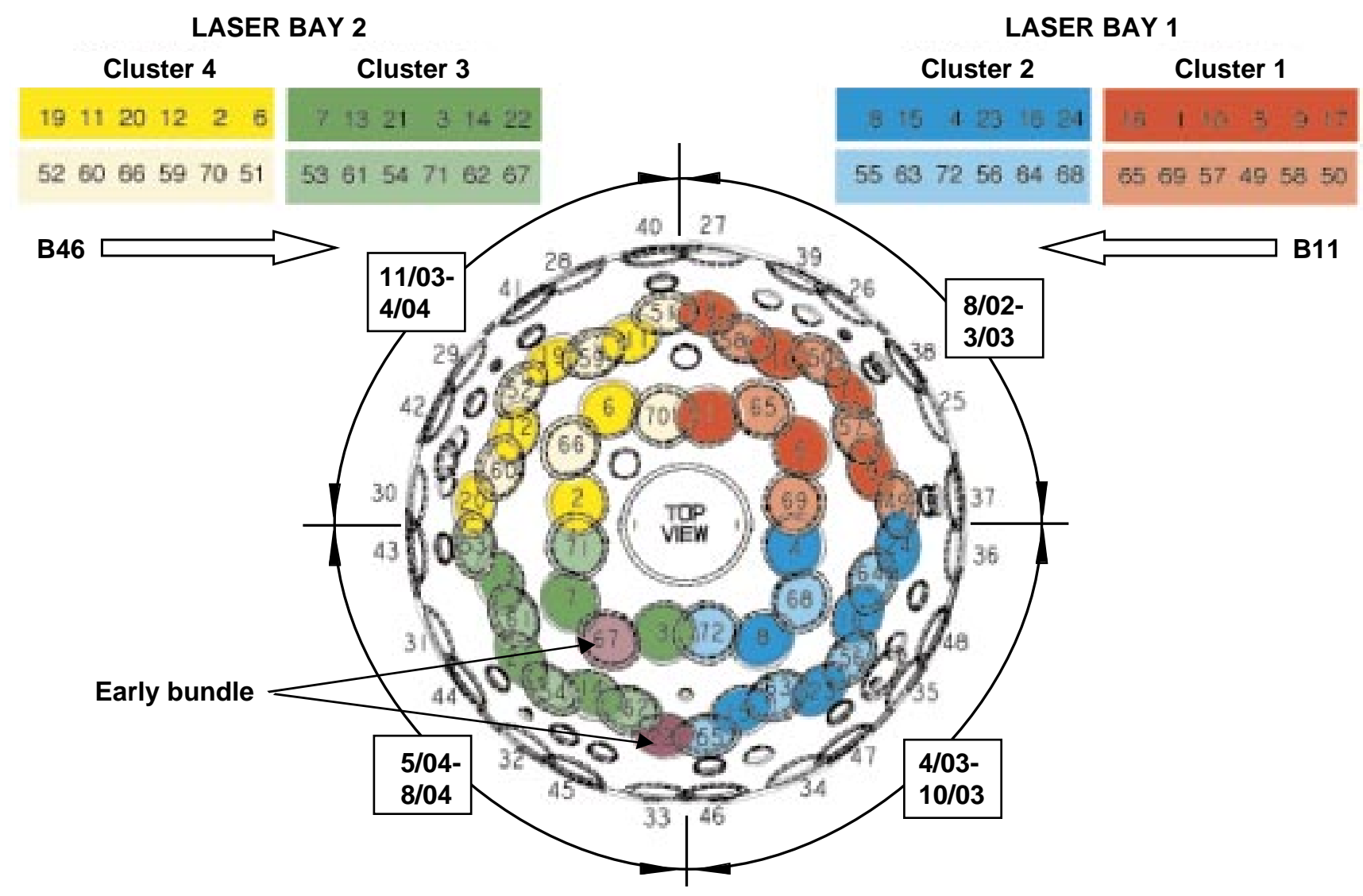

Figure 9. Time schedule of the target irradiation symmetry resulting from the start-up sequence shown in figure 7. Full symmetry will not be available until completion of the start-up activities by the end of FY04. 
It is realistic to assume that some refurbishment of optical assemblies in operational bundles will be required by the Operating Program during initial operation while installation and start up are taking place. During the installation of LRU's, the NIF Optics Assembly area operates at nearly full capacity, with limited room for maintenance and refurbishment. As the number of operating bundles and the shot rate increases during the last half of FY03, the increased refurbishment requirements nearly coincide with the drop in initial LRU installation activity. The detailed requirements for debris shield processing, and the availability of phase plates as required for target experimental campaigns are presently being analyzed by the Operating program.

\section{SUMMARY}

We presented the start-up strategy for the NIF 192-beam-line laser driver. The strategy acknowledges the linereplaceable-unit based architecture, and the modularity of the 24 individual bundles by developing plans to thoroughly test and to prealign each LRU before it is installed in the facility. One of the bundles will be started up early, to detect testing, interface, and integration problems before starting to activate the remaining 23 bundles at a completion rate of one per month. Start up of individual bundles will proceed in three distinct phases: a laser component integration phase, a laser performance qualification phase, and an on-target performance validation.

By Project completion at the end of FY'03, one laser bay will be operational, and all special equipment will be installed in the second laser bay. We expect that start up of all bundles to be completed by the end of FY'04. Individual bundles will be handed over to the ICF/NIF Program for experimental operation as they become available, following successful completion of start-up tests. Before Project completion, full performance will be demonstrated on at least one of the completed laser bundles.

This work was performed under the auspices of the United States Department of Energy by Lawrence Livermore National Laboratory under contract number W-7405-ENG-48.

\section{REFERENCES}

1. J.A. Paisner, "National Ignition Facility Conceptual Design Report", UCRL-PROP-117093 (May 1994). Available from the National Technical Information Service (NTIS), U.S. Dept of Commerce, 5285 Port Royal Rd, Springfield VA 22161.

2. U.S. Department of Energy, "The Stockpile Stewardship and Management Program, Maintaining Confidence in the Safety and Reliability of the Enduring U.S. Nuclear Weapon Stockpile," Office of Defense Programs (May 1995).

3 A.L. Hauer, R. Kauffman, A.J. Satsangi, T. Haill, R. Cauble and T.S. Saito, "Facility Use Plan of the National Ignition Facility", $1{ }^{\text {st }}$ Edition, Apr 1997, Los Alamos, LALP-97-7, UC-700.

4. B. M. Van Wonterghem, J.R. Murray, J.H. Campbell, D.R Speck, et. al., "Performance of a prototype for a large aperture multipass Nd:glass laser for inertial confinement fusion”, Appl. Opt. Vol. 36, 4832, 1997.

5. B. M. Van Wonterghem, "Start-up Plan for $1^{\text {st }}$ NIF laser bundle", UCRL-ID 130988DR, May 1998.

6. T.R. Boehly, D.L. Brown, R.J. Craxton, R.L. Keck, J.P. Knauer, J.H. Kelly, T.J. Kessler, S.A. Kumpan, S.J. Loucks, S.A. Letzring, F.J. Marshall, “Optics Communications”, 133 pp.495-506 (1997). 